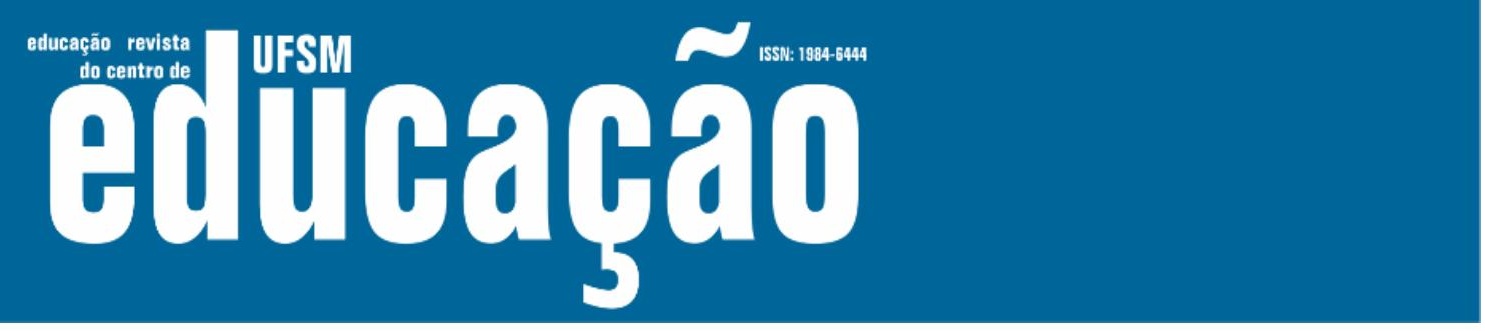

ISSN: 1984-6444 | http://dx.doi.org/10.5902/1984644439445

\title{
Movimentos da Análise Textual Discursiva em pesquisas de Educação Ambiental
}

\author{
Movements of Discursive Textual Analysis in researches into \\ Environmental Education
}

\section{Maria do Carmo Galiazzi}

Professora doutora na Universidade Federal do Rio Grande. Rio Grande, Rio Grande do Sul, Brasil. mcgaliazzi@gmail.com

\section{Elisabeth Brandão Schmidt}

Professora doutora na Universidade Federal do Rio Grande. Rio Grande, Rio Grande do Sul, Brasil. elisabethlattes@gmail.com - https://orcid.org/0000-0002-7961-7593

Recebido em 03 de dezembro de 2019

Aprovado em 19 de fevereiro de 2020

Publicado em 18 de novembro de 2020

\section{RESUMO}

O texto apresenta os movimentos de pesquisa coletiva desenvolvida em uma disciplina dos Programas de Pós-graduação em Educação da Universidade Federal do Rio Grande - FURG (PPGEC; PPGEA; PPGEDU). Está circunscrito ao exercício inerente à metodologia Análise Textual Discursiva - ATD, realizada a partir de um corpus composto por resumos de teses do Programa de Pós-graduação em Educação Ambiental da mesma universidade. $O$ objetivo deste artigo foi apresentar a descrição como atitude fenomenológica, e mostrar um movimento analítico a partir da redução eidética a categorias. A pergunta orientadora de pesquisa foi: $O$ que é isso que se mostra de Educação Ambiental nos resumos de teses do Programa de Pós-graduação em Educação Ambiental (PPGEA)? A partir de um movimento descendente de descrição dos resumos até o movimento em direção ao conceito de problematização - uma das categorias que emergiram no processo analítico - foi realizado um movimento ascendente que propiciou a interpretação e o diálogo com teóricos de diferentes epistemologias com foco no sentido atribuído à problematização.

Palavras-chave: Pesquisa qualitativa; Descrição fenomenológica; Resumos. 


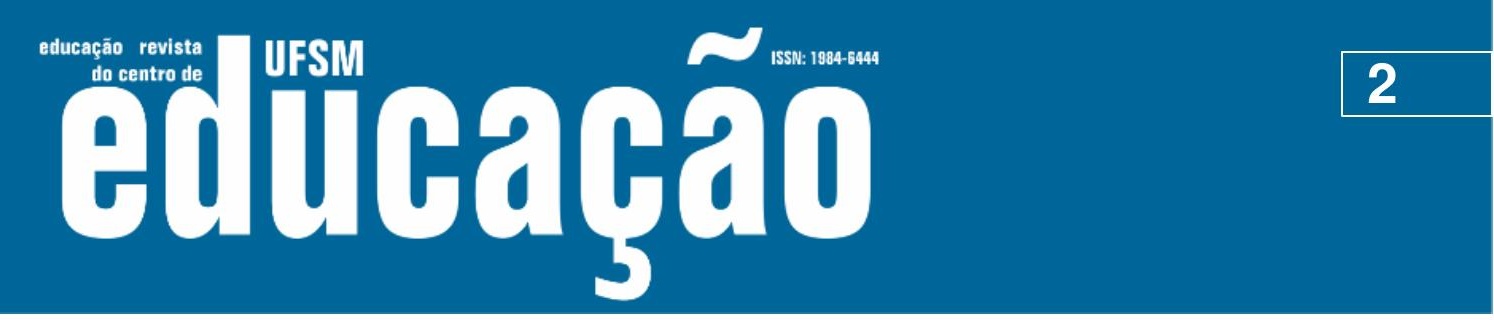

ISSN: 1984-6444 | http://dx.doi.org/10.5902/1984644439445

\section{ABSTRACT}

This paper describes movements of collective research carried out in a discipline developed in post-graduate programs in Education (PPGEC; PPGEA; PPGEDU) at the Universidade Federal do Rio Grande - FURG, located in Rio Grande, RS, Brazil. It focuses on the exercise that refers to the methodology called Discursive Textual Analysis, based on a corpus that consisted of abstracts of dissertations defended in the post-graduate program in Environmental Education at FURG from 2014 to 2018. This paper aims at introducing description as a phenomenological, attitude and at showing how to make an analytical movement based on the eidethical reduction of a category. The question that guided the study was: Which is this Environmental Education that shows itself in abstracts of dissertations of the post-graduate program in Environmental Education (PPGEA)? From the descending movement of abstract description to the movement towards the concept of problematization - one of the categories that emerged from the analytical process -, an ascending movement was carried out. It enabled interpretation and dialogue with theoreticians in different epistemologies that address "problematization" in distinct senses.

Keywords: Qualitative research; Phenomenological description; Abstracts.

\section{Introdução}

Este texto é resultado de um exercício de pesquisa qualitativa de cunho fenomenológico-hermenêutico realizado, durante o primeiro semestre de 2019, na disciplina "Análise Textual Discursiva", sob a responsabilidade das autoras, desenvolvida em uma turma que integra pós-graduandos do Programa de Pósgraduação em Educação em Ciências (PPGEC); do Programa de Pós-graduação em Educação Ambiental (PPGEA); e do Programa de Pós-graduação em Educação (PPGEDU) da Universidade Federal do Rio Grande - FURG. Intencionamos, com este artigo mostrar como fazer um movimento analítico a partir da redução nomotética ${ }^{1}$ de uma das categorias oriundas da análise realizada segundo a metodologia da Análise Textual Discursiva - ATD, proposta por Moraes e Galiazzi (2016). Em síntese, a ATD consiste na produção de unidades de significado (unitarização), seguida da aproximação de sentidos, em processos recursivos de categorização. A produção de metatextos descritivos é etapa final da metodologia de análise, momento em que as informações empíricas são articuladas com interlocutores teóricos selecionados para uma melhor compreensão do fenômeno em estudo. 


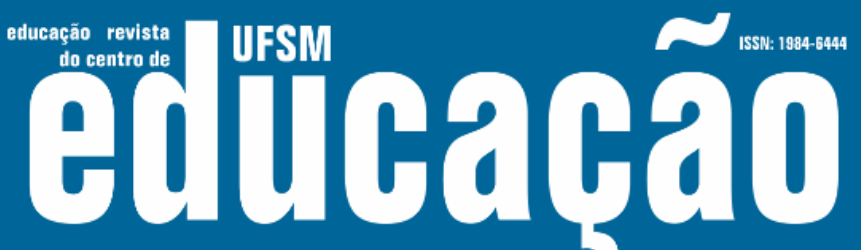

ISSN: 1984-6444 | http://dx.doi.org/10.5902/1984644439445

buscaram fundamentos teóricos especialmente na Educação Ambiental Crítica Transformadora proposta por Carlos Frederico Loureiro.

Para dar início ao movimento em direção ao que dávamos por sentido à palavra quando atribuímos este nome à categoria, buscamos ver como esta palavra está referenciada em dicionários de uso comum da Língua Portuguesa. Por aí iniciamos o movimento de pesquisa e não encontramos a palavra dicionarizada nas edições mais recentes dos dicionários Houaiss (2009) e Aurélio (2010); somente as palavras "problema", "problemático" e "problematizar" foram as que mais se aproximavam de "problematização".

Considerando problematização como a ação de problematizar, observamos que a palavra problematizar, segundo Houaiss e Villar (2009) pode remeter a três significados diferentes. O primeiro deles significa dar o caráter de problema a algo insignificante. O segundo, problematizar é tornar difícil e problemático o que não é. $O$ terceiro, problematizar é pôr em dúvida, questionar.

A problematização está no cerne da Educação Ambiental Crítica como problematização da realidade, de nossos valores, atitudes e comportamentos em práticas dialógicas, afirma Loureiro (2007, p. 69). Fundamentadas neste referencial teórico é que são apresentados os conflitos, as denúncias, as crises socioambientais, as lutas e seus enfrentamentos em muitos dos resumos analisados. Este entendimento do termo ecoa na construção lógica do método do materialismo histórico. O mesmo autor aponta para esta origem: A necessidade de problematizar a formação humana, buscando qualificá-la como educação humana plena, onilateral, e podemos trazer aqui a educação ambiental tem sido objeto de estudos na pedagogia histórico-crítica. (2016, p. 75). O verbete que consta no glossário da pedagogia histórico-crítica elaborado por Demerval Saviani (2016) articula e aproxima os dois sentidos de problematização ao afirmar que: 


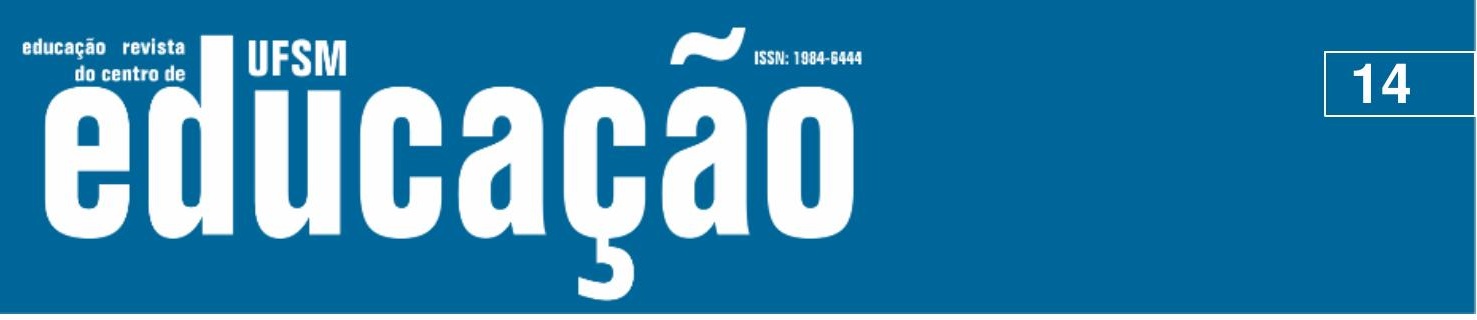

ISSN: 1984-6444 | http://dx.doi.org/10.5902/1984644439445

Daí decorre um método pedagógico que parte da prática social onde professor e aluno se encontram igualmente inseridos, ocupando, porém, posições distintas, condição para que travem uma relação fecunda na compreensão e encaminhamento da solução dos problemas postos pela prática social, cabendo aos momentos intermediários do método identificar as questões suscitadas pela prática social (problematização), dispor os instrumentos teóricos e práticos para a sua compreensão e solução (instrumentação) e viabilizar sua incorporação como elementos integrantes da própria vida dos alunos (catarse) (SAVIANI, 2016. http://www.histedbr.fe.unicamp.br/navegando/glossario/verb_c_pedagogi a_historico.htm).

Paulo Freire é referência no que concerne às proposições de uma educação problematizadora. Freire aponta para a necessidade de uma ação pedagógica que parta da realidade concreta do educando para, pelo diálogo, problematizar o seu mundo. "O que se pretende com o diálogo é a problematização do próprio conhecimento em sua indiscutível relação com a realidade concreta na qual se gera e sobre a qual incide, para melhor compreendê-la, explicá-la e transformá-la" (FREIRE, 1983b, p. 52).

Encontramos em Santos (2016) outro interlocutor o qual, a partir de viés póscrítico, aponta para a ação de problematizar em Freire quando argumenta que a ação de problematizar acontece a partir da realidade que o cerca; a busca de explicação e solução visa a transformar aquela realidade, pela ação do próprio sujeito, isto é, por meio da práxis. Nesta busca de explicação o sujeito também se transforma na ação de problematizar e passa a perceber novos problemas na sua realidade. A proposta do patrono da educação brasileira gira em torno de dois momentos: o de codificação, representado pelas situações existenciais dos educandos; e o de descodificação, que consiste na análise crítica da situação codificada. A problematização acontece no segundo momento.

Para Santos (2016), é importante ter em mente que o pós-estruturalismo contesta a autonomia do sujeito. $\mathrm{E}$ em sua tese busca articular a problematização via radicalização do fenômeno da linguagem por meio de um processo de 'desconstrução', aproximando assim problematização do modo de desconstruir proposto pelo filósofo Derrida. Assim o resumo de sua tese apresenta a problematização no campo da Educação Física escolar em outra matriz teórica: 


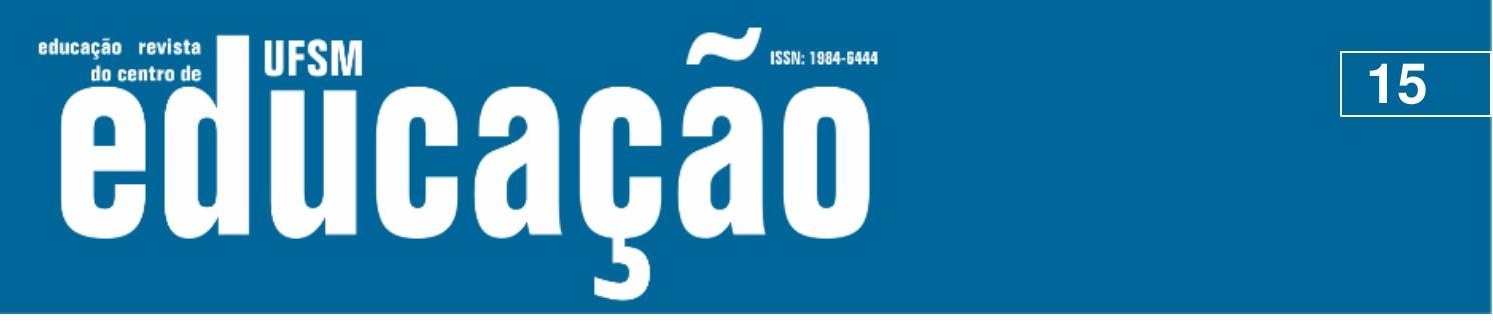

ISSN: 1984-6444 | http://dx.doi.org/10.5902/1984644439445

No currículo cultural da Educação Física, os conteúdos de ensino não são definidos a priori no planejamento uma vez que decorrem da relação dialógica entre os sujeitos participantes do processo pedagógico. A partir de "elementos disparadores" e "elementos provocadores", a problematização tece a tematização, permitindo que o currículo em ação assuma um caráter rizomático. Quanto mais se problematiza, maiores são as chances da tematização manter-se atenta ao processo de fixação simbólica, dada a intensificação da circulação dos discursos sobre as práticas corporais e seus representantes. Sob essas circunstâncias, a ação didática do(a) professor(a) é continuamente (re)centralizada, colocada em devir. Enquanto vetor que intenciona a desconstrução, a problematização permite ampliar as possibilidades de significação; suspender os regimes de verdade com que os significados operam nas diferentes épocas e contextos; atualizar a relação do sujeito consigo próprio e com o mundo, potencializando a produção de novos problemas e conceitos. Entretanto, em determinados momentos, as problematizações não enveredam para exercícios arquegenealógicos das práticas corporais, ou mesmo, chegam a apartar-se dos acontecimentos referentes às manifestações tematizadas e da voz do sujeito subjugado. Reconhecemos que as investidas contra-hegemônicas da proposta cultural da Educação Física não escapam das marcas deixadas pela maquinaria escolar. Nesse contexto, para que as diferenças possam afirmar-se, a artistagem do currículo exige que os(as) professores(as) enfrentem e se posicionem politicamente ante as inúmeras redes de força que se estabelecem nas escolas e na sociedade mais ampla e que, por vezes, tensionam ao fechamento em identidades hegemônicas. (SANTOS, 2016, p. 8)

Gallo (2006), vinculado a epistemologias pós-estruturalistas, ao apresentar um método de ensino de Filosofia para o Ensino Médio, conceitua a problematização como parte de um método de ensino em quatro etapas, sensibilização, problematização, investigação e conceituação. Sobre problematização ele afirma:

Trata-se de transformar o tema em problema, isto é, fazer com que ele suscite em cada um o desejo de buscar soluções. Na etapa anterior, o objetivo era apenas afetar, chamar a atenção, motivar - se quisermos usar uma expressão pedagógica um tanto ou quanto em desuso. Nesse segundo momento, tendo a atenção mobilizada pela questão, o objetivo é problematizá-la de vários aspectos e em várias perspectivas. Podemos, nesta etapa, promover discussões em torno do tema em pauta, propondo situações em que ele possa ser visto por diferentes ângulos e que seja problematizado em seus diversos aspectos. Nesta etapa, estimulamos o sentido crítico e problematizador da filosofia, exercitamos seu caráter de pergunta, de questionamento, de interrogação. Desenvolvemos também a desconfiança em relação às afirmações muito taxativas, em relação às certezas prontas e às opiniões cristalizadas. Quanto mais completa a problematização, mais intensa será a busca por conceitos que possam nos ajudar a dar conta do problema. (GALLO, 2006, p. 27). 


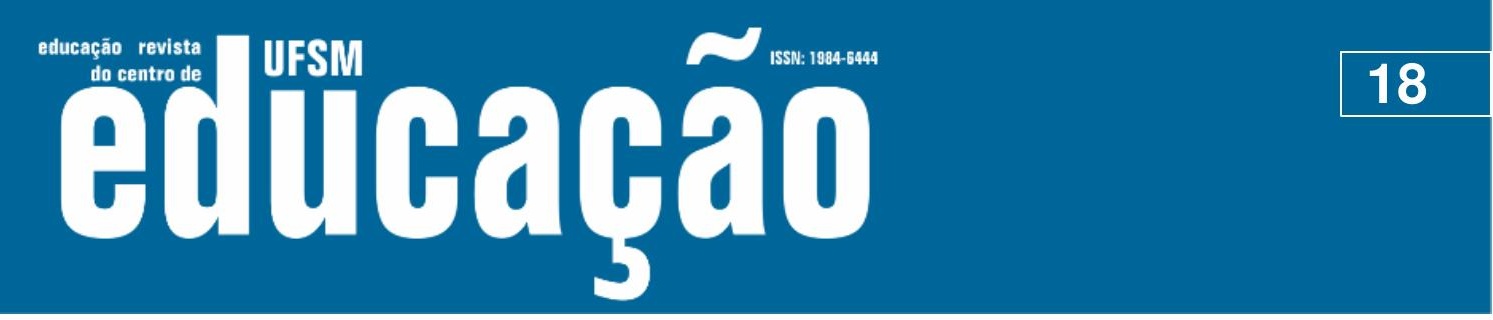

ISSN: 1984-6444 | http://dx.doi.org/10.5902/1984644439445

Esperamos, com este artigo, inspirar pesquisadores com temáticas inseridas no campo da Educação Ambiental a assumir a problematização com vistas a questionar intenções e ações de pesquisa. Mesmo que o resultado deste exercício tenha como foco resumos de teses em Educação Ambiental, estende esta possibilidade a outros campos de pesquisa.

E para fechar o círculo hermenêutico que pretendemos mostrar, lembrando que para Foucault problematizar era tornar difícil o que poderia parecer fácil demais (VINCI, 2015), retornamos do conceito à palavra, pois, foi este um dos sentidos dicionarizados apresentados no artigo. Com isso entendemos ter alcançado o objetivo do artigo que foi o de mostrar um exercício de análise na ATD.

\section{Referências}

FERREIRA, Aurélio Buarque de Holanda. Dicionário Aurélio da Língua Portuguesa. 5. ed. Curitiba: Positivo, 2010.

FREIRE, Paulo. Extensão ou Comunicação? 8. ed. Rio de Janeiro: Paz e Terra, 1983b.

GALLO, Sílvio. A Filosofia e seu ensino: conceito e transversalidade. ETHICA, v.13, n.1, p.17-35, 2006.

GALLO, Sílvio. O efeito Foucault em Educação. Pro-Posições v. 25 n. 2 Campinas. maio/agosto 2014. Editorial.

HOUAISS, Antonio; VILLAR, Mauro de Salles. Dicionário Houaiss de Língua Portuguesa. Rio de Janeiro: Objetiva, 2009.

LOUREIRO, Carlos Frederico B. Educação Ambiental Crítica: Contribuições e desafios. In: Vamos cuidar do Brasil: conceito s e práticas em educação ambiental na escola. Brasília: Ministério da Educação, Coordenação Geral da Educação Ambiental: Ministério do Meio Ambiente, Departamento de Educação Ambiental: UNESCO, 2007.

LOUREIRO, Carlos Frederico B; TOZONI-REIS, Marília Freitas de Campos. Teoria Social Crítica e Pedagogia Histórico-Crítica: contribuições à educação ambiental. Rev. Eletrônica Mestrado em Educação Ambiental. E-ISSN 1517-1256, Ed. Especial, julho/2016.

MORAES, Roque; GALIAZZI, Maria do Carmo. Análise Textual Discursiva. 3. ed. rev. e ampl. ljuí: Ed. Unijuí, 2016. (Coleção educação em ciências). 


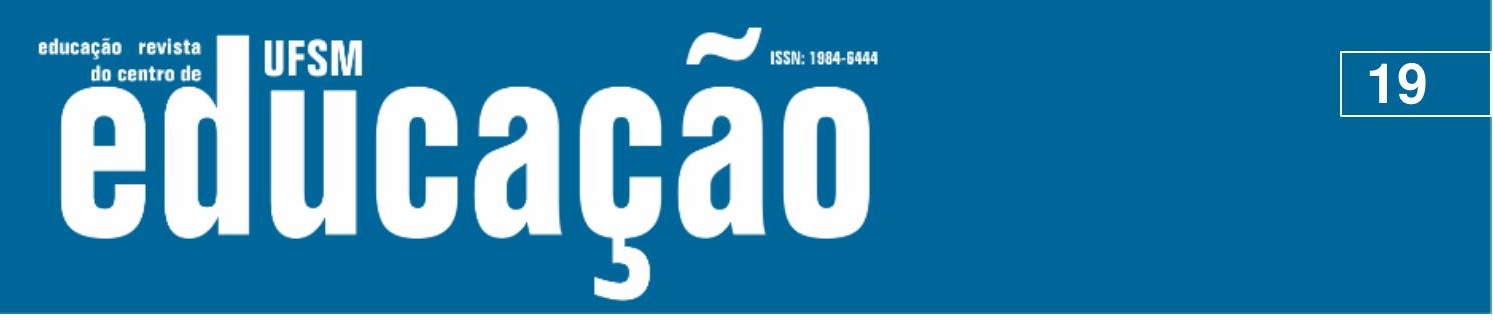

ISSN: 1984-6444 | http://dx.doi.org/10.5902/1984644439445

NEVES, Marcos Cesar Danhoni. An ideographic and nomothetic comprehension of the nature of science by science theachers. Acta Scientiarum. 21 (1): 107-112, 1999.

SANTOS, Ivan Luis dos. A tematização e a problematização no currículo cultural da Educação Física. Universidade de São Paulo. São Paulo: s. n., 2016. Tese de doutorado.

SAVIANI, Dermerval. Escola e Democracia. Edição Comemorativa. Campinas: Autores Associados, 2008.

SAVIANI, Dermeval. Exposição na Mesa Redonda Marxismo e Educação: Fundamentos Marxistas da Pedagogia Histórico-Crítica realizada no VII Colóquio Internacional Marx e Engels, no IFCH-UNICAMP em julho de 2012.

SAVIANI, Dermeval. In: GLOSSÁRIO. História, Sociedade e Educação no Brasil. Disponível em: http://www.histedbr.fe.unicamp.br/navegando/glossario/verb_c_pedagogia_historico. htm. Acesso em: 23 de junho de 2019.

$\mathrm{VINCl}$, Christian Fernando Ribeiro Guimarães. A problematização e as pesquisas educacionais: sobre um gesto analítico foucaultiano. Filosofia e Educação [rfe] v. 7, n. 2. Campinas, SP junho/setembro de 2015, p. 195-219.

\section{Correspondência}

Maria do Carmo Galiazzi — Universidade Federal do Rio Grande - Av. Itália, s/n Km 8, Carreiros, Rio Grande, Rio Grande do Sul, Brasil.

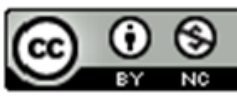

This work is licensed under a Creative Commons Attribution-NonCommercial 4.0 International (CC BY-NC 4.0)

\section{Notas}

\footnotetext{
${ }^{1}$ Derivado de nomos, cujo significado é o uso de leis, nomotético tem o sentido de elaboração de leis ou princípios derivados de conhecimento de fatos anteriores.

${ }^{2}$ Apresentam-se as Unidades de Significado na sequência em que aparecem nos resumos que compõem o corpus de análise. Foram retiradas informações do texto que, a nosso ver, não têm relação com a pergunta. Cabe ressaltar que adaptações foram feitas no texto do resumo de modo a torná-lo descritivo. Cada resumo foi identificado com um nome fictício de uma espécie inventada de coruja. O animal escolhido foi a coruja por ser o símbolo do PPGEA. Os nomes das corujas têm relação com as temáticas trabalhadas nas pesquisas.
} 